\title{
Influence of Gauge Face Worn Profile and Lubrication on Vehicle/Track Interaction
}

\begin{abstract}
Makoto ISHIDA
Senior Researcher, Laboratory Head, Assistant Senior Researcher,

Track Dynamics, Railway Dynamics Div.

Mitsunobu TAKIKAWA

\author{
Fusayoshi AOKI \\ Researcher,
}

\author{
Yasutomo SONE
tant Senior Researcher, \\ Yasutomo SONE
Assistant Senior Researcher, \\ Lubricanting Materials, Materials Technology Div.
}

The vehicle/track interaction caused by a vehicle negotiating a sharply curved track is very important to analyze vehicle running stability and materials integrity. Wheel flange /gauge face wear is influenced by the vehicle/track interaction, such as the attack angle of wheelset and lateral force interacting between wheel and rail, while the worn profiles of flange and gauge corners have an influence on vehicle/track interaction. In this study, some track site measurements have been carried out for two years on Shinkansen sharp curved tracks to investigate the influence of gauge face wear on vehicle / track interaction, and also on narrow-gauge sharp curved tracks to investigate the effect of lubrication on vehicle/track interaction. This paper describes the detailed arrangements and results of measurements.
\end{abstract}

Keywords : gauge face wear, lubrication, attack angle, lateral force, track site measurement

\section{Introduction}

Renewing worn high rails at sharply curved tracks has a relatively significant influence on maintenance costs. It is important to clarify some factors that progress the wear of high rails, and predict and estimate the amount of gauge face wear based on the effect of those factors ${ }^{1)}$, because preventive grinding has a great effect on reducing rolling contact fatigue defects called squats ${ }^{2) 3)}$. It is expected that the prediction of gauge face wear will effectively reduce the scheduled maintenance work and costs. The authors focus on the effect of dynamic vehicle/ track interaction, such as lateral force, attack angle, and others, on the amount of wear. The dynamic measurements were carried out at three track sites. The two track sites were selected as representatives of severe wear condition without lubrication on Shinkansen sharply curved tracks whose radii of curve were $400 \mathrm{~m}$ and $900 \mathrm{~m}$. The other track site was selected as a representative of sharply curved narrow-gauge tracks with lubrication. Though lubrication has been carried out so far on high rail to prevent gauge face wear, its effect has not been widely reported on. Some reports on the effect of low rail lubrication on preventing rail corrugations have only recently been published ${ }^{4)}$. On the other hand, the effect of high rail lubrication on flange climb derailment at low speed has frequently been focused on. This paper describes the detailed arrangements and results of measurements.

\section{Dynamic measurements focusing on worn profiles}

\subsection{Test arrangements}

The measurements were carried out at two
Shinkansen track sites whose radii of curve were $400 \mathrm{~m}$ and $900 \mathrm{~m}$. In the measurements, the wheel load, lateral force, the lateral deflection of railhead and attack angle of vehicle wheelset were measured. The layout of test arrangements at one track site is shown in Figure 1 and some detailed information is given in Table 1 . The cant deficiency at the measurement site of $400 \mathrm{~m}$-curved track is about $25 \mathrm{~mm}$ and that of $900 \mathrm{~m}$-curved track is about $20 \mathrm{~mm}$. Table 2 shows the technical details of the vehicle whose dynamic response was obtained in the measurements and the running speed of the vehicles.

The dynamic measurements at $400 \mathrm{~m}$ curved track

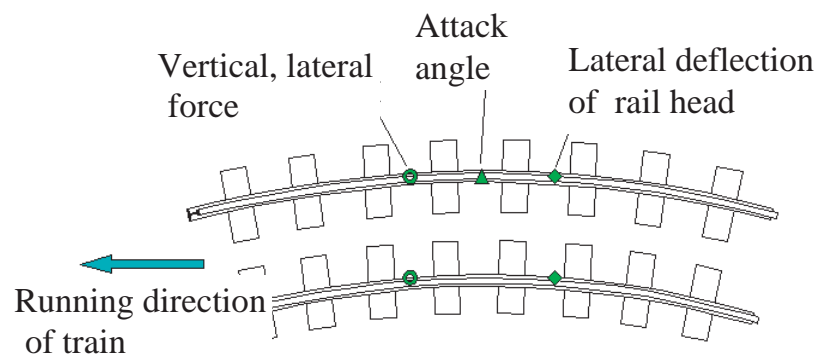

Fig. 1 Layout of measurement track site in Shinkansen track

Table 1 Detailed measurement arrangements of two tracks

\begin{tabular}{|c|c|c|c|c|c|}
\hline \multirow{2}{*}{$\begin{array}{c}\text { Curve } \\
\text { radius } \\
(\mathrm{m})\end{array}$} & $\begin{array}{c}\text { Rail } \\
\text { type }\end{array}$ & $\begin{array}{c}\text { Cant } \\
(\mathrm{mm})\end{array}$ & \multicolumn{4}{|c|}{$\begin{array}{l}\text { Accumulated passing tonnage } \\
\text { (MGT: Million Gross Tonnage })\end{array}$} \\
\hline 400 & $\begin{array}{c}\text { JIS60 } \\
\text { (Heat- }\end{array}$ & 95 & 0.5 & 2.3 & - \\
\cline { 4 - 6 } & & 35 & 1.4 & 2.5 & 75 \\
\hline
\end{tabular}


Table 2 Technical details of vehicles for measurements

\begin{tabular}{|c|c|c|c|}
\hline Vehicle type & Old & New & Special \\
\hline $\begin{array}{c}\text { Static wheel } \\
\text { load }\end{array}$ & $85 \mathrm{kN}$ & $65 \mathrm{kN}$ & $55 \mathrm{kN}$ \\
\hline Wheel tread & Cone & Arc & $\begin{array}{c}\text { Arc } \\
(400 t y p e)\end{array}$ \\
\hline $\begin{array}{c}\text { Wheel } \\
\text { diameter }\end{array}$ & $910 \mathrm{~mm}$ & \multicolumn{2}{|c|}{$860 \mathrm{~mm}$} \\
\hline Wheel base & \multicolumn{2}{|c|}{$2500 \mathrm{~mm}$} & $2250 \mathrm{~mm}$ \\
\hline Bogie type & Direct mount & \multicolumn{3}{|c|}{ Bolsterless } \\
\hline Speed & \multicolumn{4}{|c}{$65 \mathrm{~km} / \mathrm{h}$} \\
\hline
\end{tabular}

were performed just after rail renewal and after 23 MGT (MGT: million gross tonnage $=$ the axle load multiplied by the number of passing axles) and those at $900 \mathrm{~m}$ curved track were just after rail renewal, after $23 \mathrm{MGT}$ and 76 MGT. In addition, profile measurements were carried out at a $400 \mathrm{~m}$ curved track site which was very close to the dynamic measurement site.

\subsection{Test results}

\subsubsection{Profiles of worn rails}

Figure 2 shows the progress of the amount of wear on the gauge face installed on sharply curved tracks of $400 \mathrm{~m}$ and $900 \mathrm{~m}$ radii of curve. In this Figure, the wear progress of $400 \mathrm{~m}$ curved track is roughly three times as much as that of $900 \mathrm{~m}$ curved track. Figure 3 shows the progress of worn profile of $400 \mathrm{~m}$ curved track and $900 \mathrm{~m}$ curved track compared with the original profile of JIS 60 rail.

Next, Figure 4 (a) shows the matching of worn profiles of the rail of $400 \mathrm{~m}$ curve radius track about 58 MGT of accumulated passing tonnage and the worn wheel profiles of three types of vehicles about $0.1 \times 10^{6} \mathrm{~km}$ running distance. Figure 4 (b) also shows the radii of curve of

$$
\frac{1}{R}=-\frac{\frac{d^{2} y}{d x^{2}}}{\left\{1+\left(\frac{d y}{d x}\right)^{2}\right\}^{\frac{3}{2}}}
$$

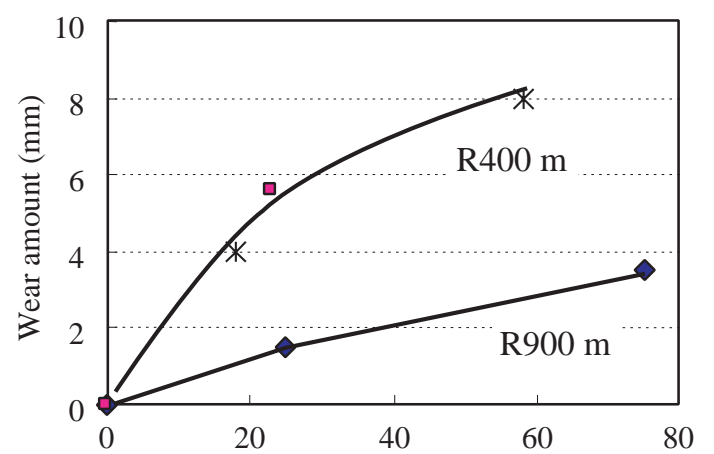

Accumulated passing tonnage (MGT : Million Gross Tonnage)

Fig. 2 Variation of high rail wear amount of $400 \mathrm{~m}$ and 900 m curve radius track with accumulated passing tonnage
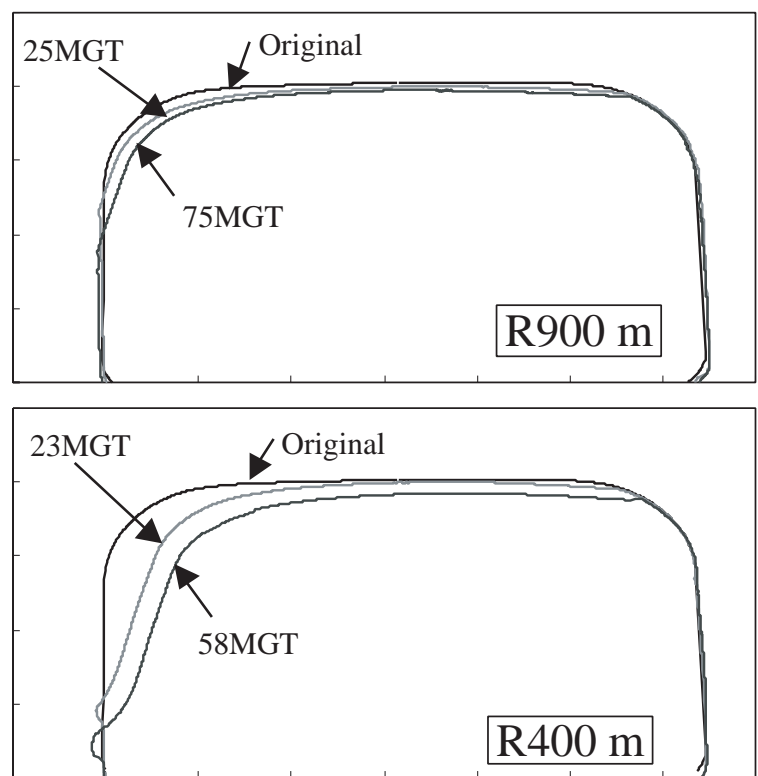

Fig. 3 Progress of worn profile of $400 \mathrm{~m}$ curved track and $900 \mathrm{~m}$ curved track compared with an original profile

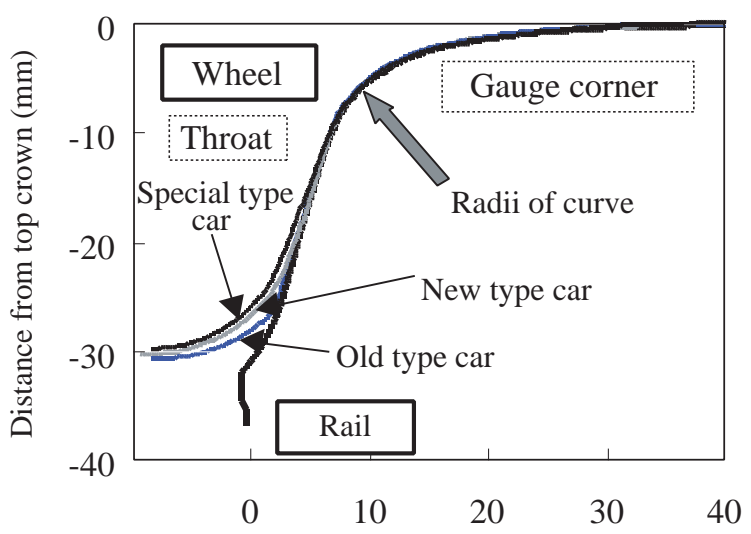

Distance from gauge corner $(\mathrm{mm})$

(a) Matching of worn profiles of rail and wheel

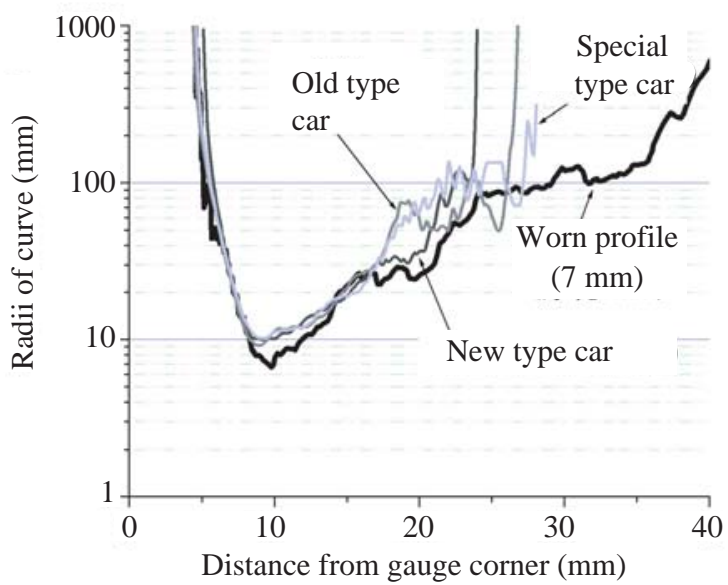

(b) Radii of curve of worn profiles of rail and wheel

Fig. 4 Matching and configurations between worn profiles of rail and wheel 
the same rail profiles and wheel profiles as those in Figure 4 (a). The radii of curve is calculated with the equation (1). The origin of abscissa, that represents the positions of rail head, is adopted as the gauge corner at $14 \mathrm{~mm}$ below the rail crown which is the position of measuring track gauge and may cover the main contact region between rail and wheel. In the Figure of the matching of worn profiles of rail and wheel, all profiles at the contact area are very close to each other. Also in the Figure of the radii of curve of rail and wheel profiles, the rail radii of curve is smaller than the wheel ones from 10 to $25 \mathrm{~mm}$ of the positions in the horizontal axis, which means rail gauge corner smoothly contacts the wheel throat of flange.

\subsubsection{Lateral force of high rails}

Figure 5 shows the lateral forces of new and worn high rails caused by leading axles of various types of cars at the curved tracks with a radius of $400 \mathrm{~m}$ and $900 \mathrm{~m}$. The lateral forces of high rail at curved track whose radii of curve is $400 \mathrm{~m}$ are almost twice that at $900 \mathrm{~m}$ curve radius track on account of lateral forces due to curve negotiation because the cant deficiency is almost the same for the two curved tracks. In this Figure, the top, bottom and middle lines represent the maximum, minimum and average lines, respectively. The lateral forces of worn rail at $400 \mathrm{~m}$ curve radius track tend to be stabler than that of new rail. On the other hand, this tendency is not clear for the lateral forces of worn rail at $900 \mathrm{~m}$ curve radius track, because the tendency for the lateral forces may be different at the first and second measurements of wear amount. The next measurements will be expected to make the tendency of $900 \mathrm{~m}$ curve radius track clear.

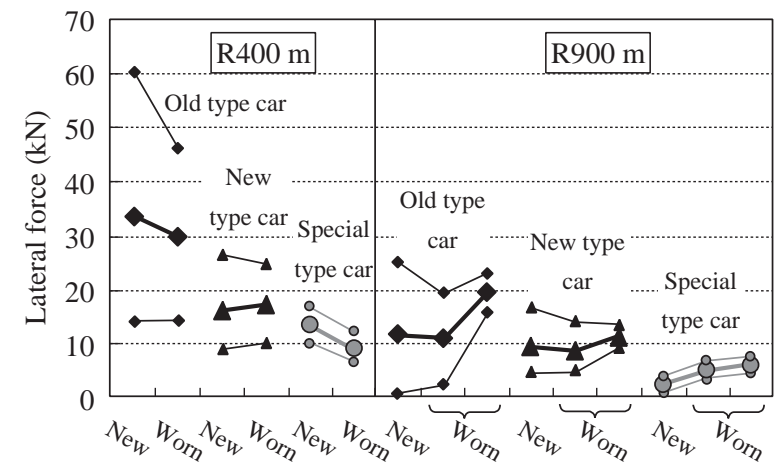

Fig. 5 Lateral forces of new and worn high rails caused by leading axles of various types of cars at curved tracks with a radius of $400 \mathrm{~m}$ and $900 \mathrm{~m}$

\subsubsection{Lateral deflection of high rail}

Figure 6 shows the lateral deflections (lateral displacement of railhead) of new and worn high rails caused by leading axles at the curved tracks with a radius of $400 \mathrm{~m}$ and $900 \mathrm{~m}$. The plus sign of the deflection means the outward direction of gauge, and the minus sign means the inward direction in this Figure. Since lateral deflections should be almost proportional to lateral forces and old type cars should generate larger lateral forces than newer cars do, deflections caused by old type cars are larger than those by newer type cars. Also, two interesting phenomena were observed at $900 \mathrm{~m}$ curve radius track. One was that some lateral deflections of high rail showed

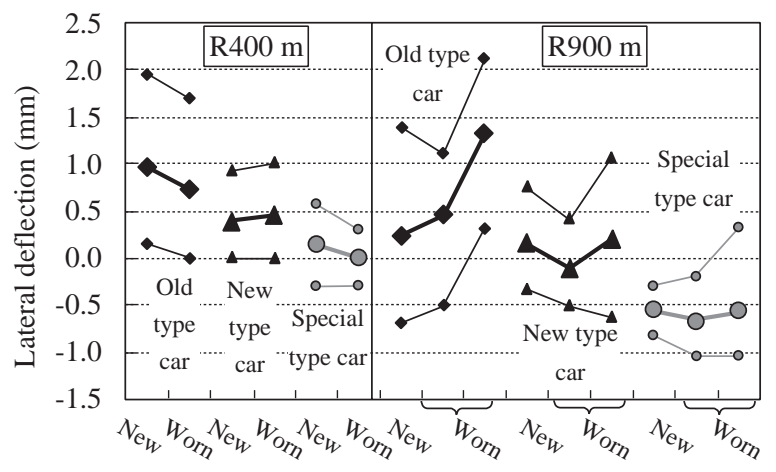

Fig. 6 Lateral deflections (lateral displacement of railhead) of new and worn high rails caused by leading axles at curved tracks with a radius of $400 \mathrm{~m}$ and $900 \mathrm{~m}$

the inward direction, and the other was that the deflections of worn rails scattered more than that of new rails. Generally, the lateral deflection of high rails shifts outward due to the lateral force, but the lateral deflection can shift inward when the lateral force is small, depending on the position of rail/wheel contact and the magnitude of wheel load. A further investigation is expected to clarify the reason why these deflections of worn rails scatter in wide ranges.

\subsubsection{Attack angle of high rail}

Figure 7 shows the attack angles of new and worn high rails caused by the leading axles on the curved tracks with a radius of $400 \mathrm{~m}$ and $900 \mathrm{~m}$. The attack angle of worn rails at curved track of radius $900 \mathrm{~m}$ was measured only after accumulated passing tonnage of $75 \mathrm{MGT}$, and the amount of gauge face wear was $3.5 \mathrm{~mm}$ at that time. The other kinds of measured data were obtained after 25 MGT and 75 MGT. In this Figure, the attack angles of worn rails are smaller than that of new rails irrespective of the rolling stock type. Also, the attack angles of $400 \mathrm{~m}$ curve radius track were similar to those of $900 \mathrm{~m}$ curve radius track. When the lateral forces shown in Fig. 5 are considered, the difference of high rail wear amount between $400 \mathrm{~m}$ and $900 \mathrm{~m}$ curve radius tracks investigated in this study could have been caused mainly by lateral forces.

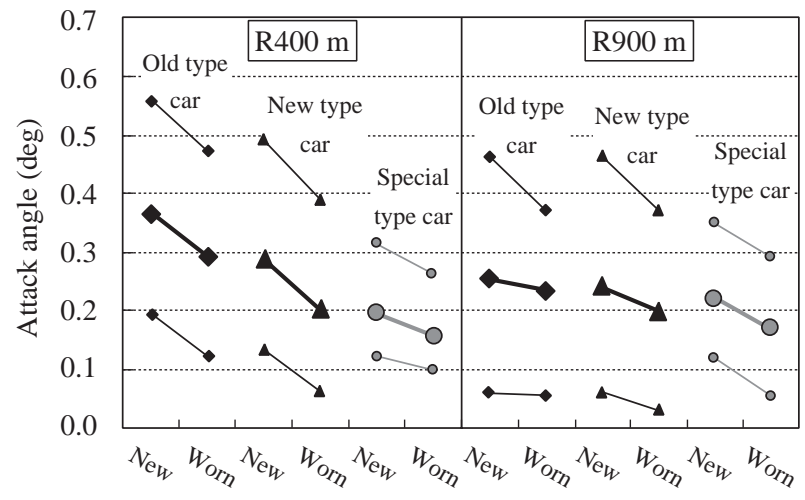

Fig. 7 Attack angles of new and worn high rails caused by leading axles at curved tracks with a radius of $400 \mathrm{~m}$ and $900 \mathrm{~m}$ 


\subsubsection{Derailment factor of high rail}

Figure 8 shows the derailment factor, which is defined as lateral/vertical forces of new and worn high rails caused by the leading axles on the curved tracks with a radius of $400 \mathrm{~m}$ and $900 \mathrm{~m}$. Since the derailment factor is mostly influenced by the lateral force, its tendency of $400 \mathrm{~m}$ curve radius track looks stabler than that of $900 \mathrm{~m}$ curve radius track in this Figure. Its tendency of $900 \mathrm{~m}$ curve radius track is not clear. A further investigation is expected to clarify its tendency, lateral forces and lateral deflections of worn high rails.

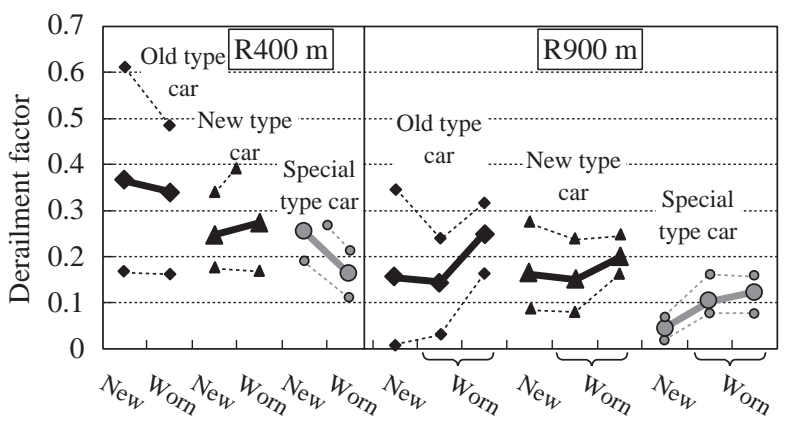

Fig. 8 Derailment factor of new and worn high rails caused by leading axles at curved tracks with a radius of $400 \mathrm{~m}$ and $900 \mathrm{~m}$

\section{Dynamic measurements focusing on lubrication}

\subsection{Test arrangements}

Figure 9 shows the location of track site for measurements, which is a narrow-gauge track whose radius of curve is $400 \mathrm{~m}$. Dynamic wheel loads, lateral forces, lateral deflections of rail head and the attack angles of wheelset of leading axle were measured with and without normal lubrication at the test track site. The lubricator normally used at the test track site was temporarily stopped for about a month to realize the condition of no lubrication. Table 3 gives the detailed measurement arrangements of track. Table 4 also gives the technical details of vehicles which were objectives for measurements. Figure 10 shows the worn profile of rail at the track site. In this Figure, the wear amount of gauge corner is about $3 \mathrm{~mm}$ from the original profile. Figure 11 shows the amount of remaining lubricant on the rail surface. In this Figure, almost no lubricant is confirmed for the condition of no lubrication and a sufficient amount
Table 3 Detailed measurement arrangements of track

\begin{tabular}{|c|c|c|c|c|c|}
\hline $\begin{array}{c}\text { Curve } \\
\text { radius } \\
(\mathrm{m})\end{array}$ & $\begin{array}{c}\text { Rail } \\
\text { type }\end{array}$ & $\begin{array}{c}\text { Cant } \\
(\mathrm{mm})\end{array}$ & $\begin{array}{c}\text { Distance from } \\
\text { the lubricator } \\
(\mathrm{m})\end{array}$ & $\begin{array}{c}\text { Lubrication arrangement } \\
\text { of high rail }\end{array}$ \\
\hline \multirow{2}{*}{400} & $\begin{array}{c}\text { JIS50N } \\
(\text { Heat- } \\
\text { treated })\end{array}$ & 100 & 48 & $\begin{array}{c}1^{\text {st }} \\
\text { measurement }\end{array}$ & $\begin{array}{c}2^{\text {nd }} \\
\text { measurement }\end{array}$ \\
\hline
\end{tabular}

Table 4 Technical details of vehicles which were objectives for measurements

\begin{tabular}{|c|c|c|c|c|c|}
\hline Vehicle type & Express & TypeA & TypeB & TypeC & Rapid \\
\hline $\begin{array}{c}\text { Static wheel } \\
\text { load }\end{array}$ & $55 \mathrm{kN}$ & $55 \mathrm{kN}$ & $45 \mathrm{kN}$ & $45 \mathrm{kN}$ & $45 \mathrm{kN}$ \\
\hline Wheel tread & \multicolumn{2}{|c|}{ Cone } & \multicolumn{3}{|c|}{ Modified arc } \\
\hline Wheel diameter & \multicolumn{5}{|c|}{$860 \mathrm{~mm}$} \\
\hline Wheel base & \multicolumn{5}{|c|}{$2100 \mathrm{~mm}$} \\
\hline Bogie type & Direct mount & Bolsterless \\
\hline Speed & \multicolumn{5}{|c|}{$70 \sim 80 \mathrm{~km} / \mathrm{h}$} \\
\hline
\end{tabular}

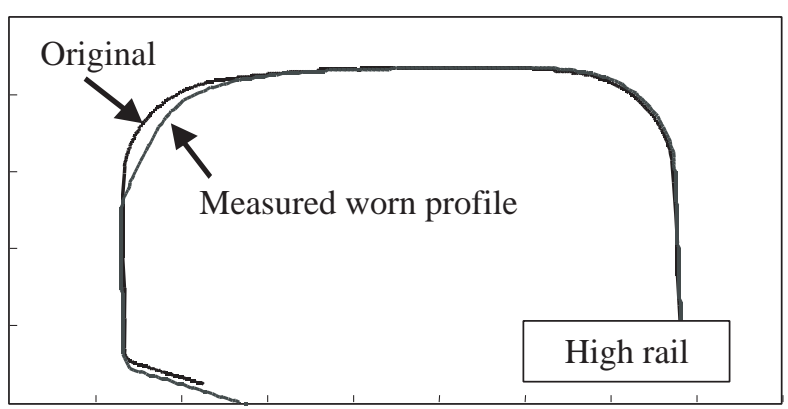

Fig. 10 Worn profile of rail at the track site

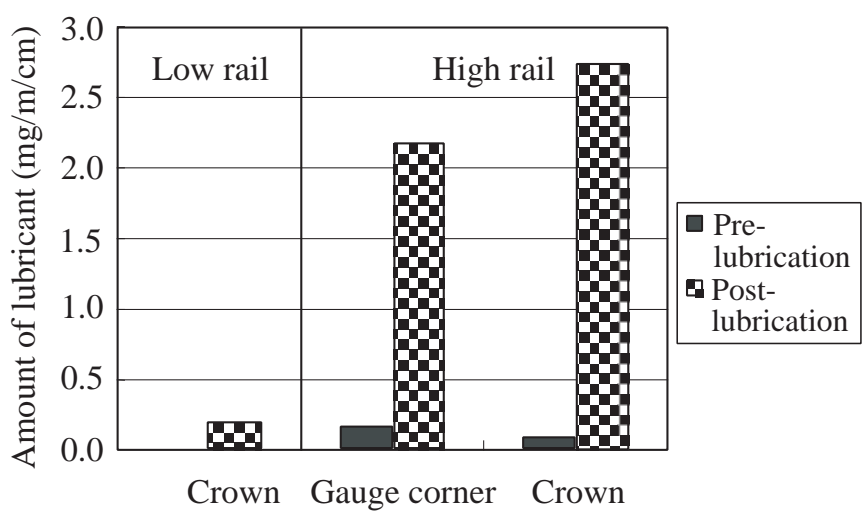

Fig. 11 Amount of remaining lubricant on rail surface

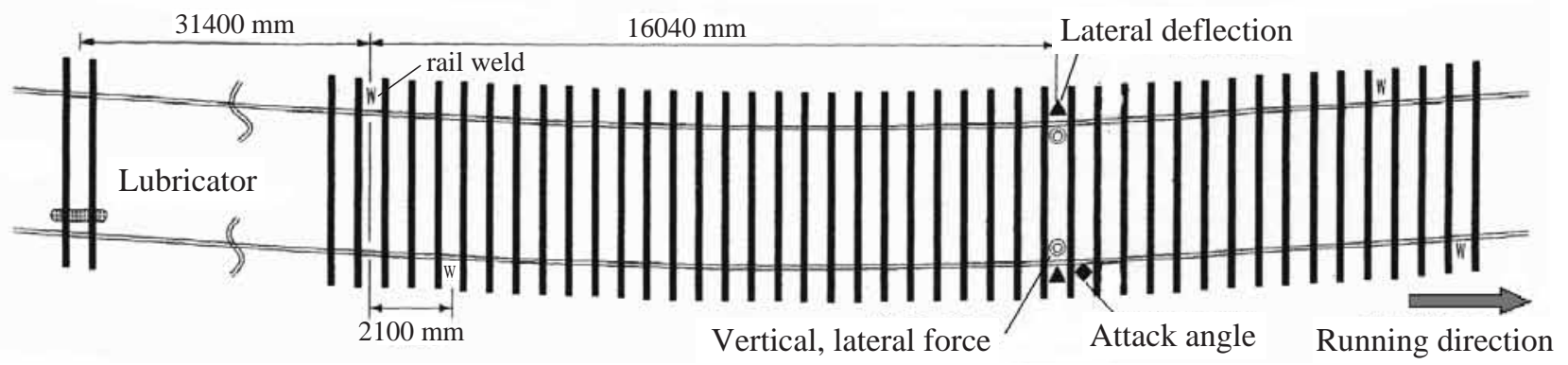

Fig. 9 Location of track site, which is a narrow-gauge track whose radius of curve is $400 \mathrm{~m}$, for measurements 
of lubricant is confirmed for the lubrication condition.

\subsection{Test results}

\subsubsection{Lateral force of high rails}

Figure 12 shows the lateral forces caused by leading axles of various types of cars under the condition of lubrication and no lubrication, in which the top and bottom dotted lines and middle solid line represent the maximum, minimum and average of obtained data. In this Figure, the magnitude and variation of lateral forces of high rail under lubrication are larger than those under the condition of no lubrication irrespective of vehicle types. The reason may be the fact that steering performance became worse because the guiding force of the vehicle obtained from the longitudinal friction between wheel and rail decreased.

\subsubsection{Lateral deflection of high rail}

Figure 13 shows the lateral deflections (lateral displacement of railhead) caused by leading axles of various types of cars under the condition of lubrication and no lubrication. The plus sign of the deflection means the outward direction of gauge, and the minus sign means the inward direction in this Figure. In this Figure, lateral deflections are increased by lubrication, since lateral deflections should be almost proportional to lateral forces which are increased by lubrication as shown in Figure 12. When the magnitude of lateral forces shown in Figure 12 is considered, lateral deflections of high rail are into the inward direction in the case of lateral forces less than $5 \mathrm{kN}$ as well as some data shown in Figure 6 . This phenomenon basically depends on the position of rail/ wheel contact and the magnitude of wheel load.

\subsubsection{Attack angle of high rail}

Figure 14 shows the attack angles caused by leading axles of various types of cars under the condition of lubrication and no lubrication. In this Figure, the variation of attack angles under lubrication are larger than those under the condition of no lubrication as a whole, but the average of them under lubrication are almost the same as those under the condition of no lubrication. Basically attack angles can be increased under lubrication because the guiding forces of vehicle obtained from the longitudinal friction between wheel and rail decrease. However, such a tendency of attack angles is not clearly identified in the measurements. A further study is expected on the effect of lubrication on attack angles.

\subsubsection{Derailment factor of high rail}

Figure 15 shows the derailment factor, which is defined as lateral/vertical forces, caused by leading axles of various types of vehicles under the condition of lubrication and no lubrication. In this Figure, the derailment factors under lubrication are larger than those under the condition of no irrespective of vehicle types as a whole. However, even if the derailment factor is large under lubrication, the safety against derailment is ensured since the friction coefficient at the gauge corner is small enough. When the difference of derailment factor among vehicle types is considered, the steering perfor-

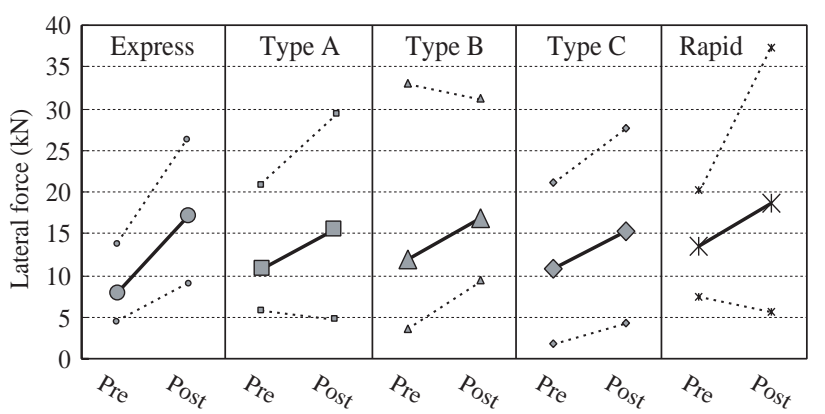

Fig. 12 Lateral forces caused by leading axles of various types of cars with and without lubrication

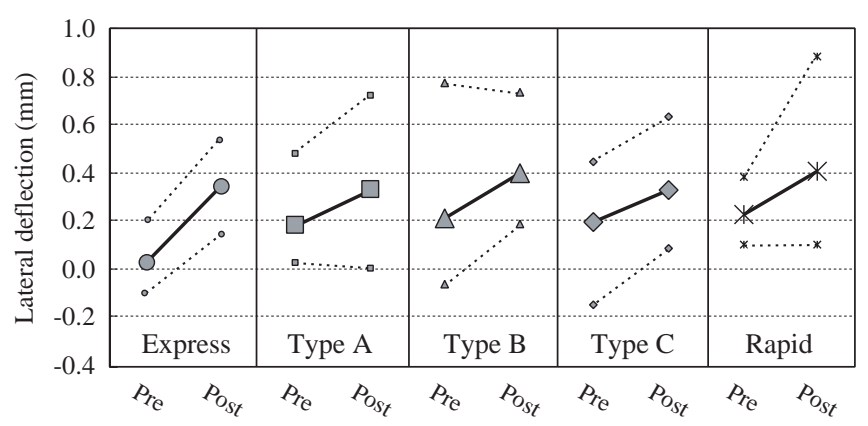

Fig. 13 Lateral deflections (lateral displacement of railhead) caused by leading axles of various types of cars with and without lubrication

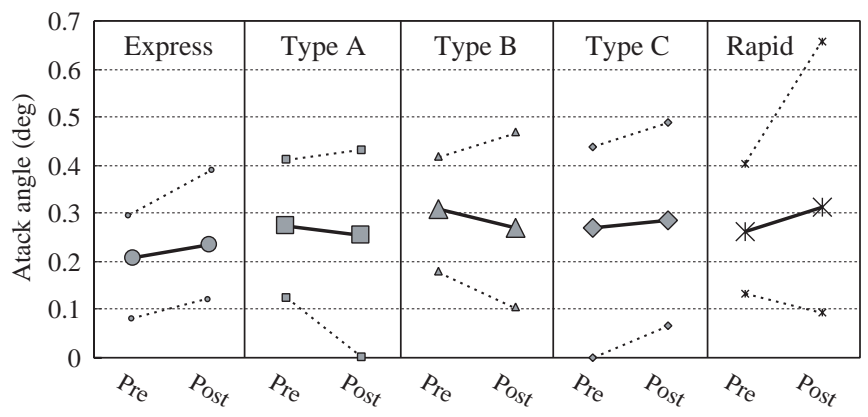

Fig. 14 Attack angles caused by leading axles of various types of cars with and without lubrication

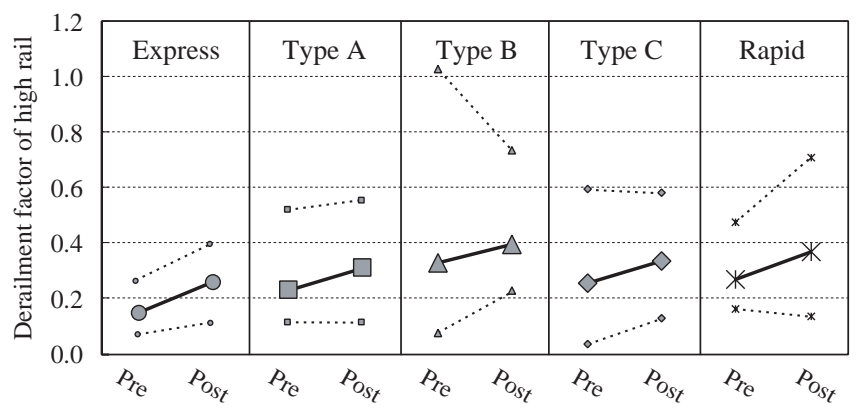

Fig. 15 Derailment factor, which is defined as lateral/ vertical force, caused by leading axles of various types of cars with and without lubrication 
mance and wheel load of the vehicle may also have some effect on the derailment factor. The effect of the vehicle performance on the derailment factor must be investigated further.

\section{Concluding Remarks}

The investigation and dynamic measurements on a Shinkansen standard gauge track have been carried out to study the influence of gauge face wear on the wheel/ rail dynamic behaviour, and also on a conventional narrow-gauge track to study the influence of lubrication on the wheel/rail dynamic behaviour. By analysing the data obtained in this study, the following findings were newly identified.

(1) Influence of rail gauge face wear on wheel/rail dynamic behaviour

(a)The relation between gauge face wear and lateral force was not clearly identified. However, the tendency of the slight decrease of leading axle attack angle in response to the increase of gauge face wear was identified, which may be one of the reasons for the decrease of wear rate at the high rail gauge corner together with the progress of conformity between wheel flange and rail gauge face.

(b)In the case where the lateral force is small, the lateral deflection of the head of high rail can shift inward depending on the position of rail/wheel contact and the magnitude of wheel load.

(c)In this study, the difference of the wear amount at gauge face wear between $400 \mathrm{~m}$ curve radius track and $900 \mathrm{~m}$ curve radius track should have been mainly caused by the difference of lateral forces since the difference of leading axle attack angle between two curves were very small.

(2) Influence of high rail lubrication on wheel/rail dynamic behaviour

(a)The magnitude of lateral forces of high rail under lubrication were larger than those under the condition of no lubrication irrespective of vehicle types, the reason of which may be the fact that steering performance became worse because the guiding force of vehicle obtained from the longitudinal friction between wheel and rail decreased as a result.

(b) The effect of lubrication on the increase of attack angle of leading axle was expected since the steering performance of bogie should become worse because the guiding force of vehicle obtained from the longitudinal friction between wheel and rail decreased due to lubrication. However, the effect of lubrication has not been clearly identified yet because the difference in the data was very small under the condition of lubrication and no lubrication.

(c) The derailment factors under lubrication were larger than those under the condition of no lubrication irrespective of vehicle type as a whole. However, even if the derailment factor is large under lubrication, the safety against derailment is ensured since the actual friction coefficient at gauge corner is small enough.

When the vehicle/track interaction on curved tracks is considered, the friction coefficient between wheel and rail has a very important role. Accordingly, the influence factors of friction coefficient such as temperature, humidity and surface conditions of wheel and rail should be taken into account. A further study will be expected on the interface and adhesion between wheel and rail, such as friction coefficient, related to vehicle and track dynamics.

\section{Acknowledgements}

The authors thank those who were involved in the dynamic measurements and field investigation at the track sites of East Japan Railway Company and West Japan Railway Company for their great co-operation.

\section{References}

1) Handbook of JR rolling stock (in Japanese), Rail Magazine additional edition, 1999.

2) Suda, M., Nagato, A., Tokuoka, K. and Miura, S: " New Railway Track (in Japanese)," Japan Railway Civil Engineers Association, pp.66-67, 1998.

3) Ishida, M., Takikawa, M. and Jin, Y.: " Relation between Vehicle/Track Interaction and Rail Gauge Face Wear (in Japanese)," Proc. of the $8^{\text {th }}$ Railway Technology Joint Symposium, pp.527-530, 2001.

4) Ishida, M., Moto, T. and Takikawa, M.: "Study on the Mechanism of Rail Corrugations on Low Rails at Sharp Curves, " Proc. of the International Tribology Conference Nagasaki 2000, pp.2051-2056, 2000. 